\title{
Padrão físico-químico e microbiológico da água de nascentes e poços rasos de propriedades rurais da região sudoeste do Paraná
}

\section{Physico-chemical and microbiological standards of water springs and shallow wells on rural properties in the southwest region of Paraná}

\author{
Débora Daneluz', Dinéia Tessaro ${ }^{1 *}$
}

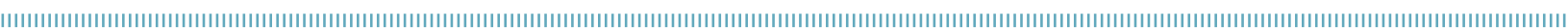

RESUMO: Este trabalho avalia a qualidade da água em propriedades rurais do município de Dois Vizinhos, Paraná, por meio de analises físico-químicas e microbiológicas. Foram analisadas 90 amostras, sendo 45 provenientes de nascentes e 45 de poços rasos, quanto aos parâmetros $\mathrm{pH}$, temperatura, turbidez, coliformes totais e termotolerantes. Das 90 amostras analisadas, 23 atenderam à legislação vigente, enquanto que 67 estavam em desacordo, logo, inapropriadas para o consumo humano e animal, representando fator de risco à saúde.

PALAVRAS-CHAVE: coliformes totais; coliformes termotolerantes; potabilidade de água.
ABSTRACT: This study evaluates the quality of water in rural farms of Dois Vizinhos, Paraná, Brazil, by physicochemical and microbiological analyses. A total of 90 samples were analysed, 45 from water springs and 45 from shallow wells, regarding the following parameters: $\mathrm{pH}$, temperature, turbidity, total and thermotolerant coliforms. Of the 90 samples analysed, 23 met the current legislation, while 67 disagreeded with it, being unsuitable for human and animal consumption and a health risk factor.

KEYWORDS: total coliforms; thermotolerant coliforms; water potability. 
A qualidade da água para consumo humano é de grande importância, e suas características microbiológicas e físico-químicas definem sua aceitabilidade pois, quando contaminada, constitui fator de risco para toda a sociedade (Germano; Germano, 2001). Associado à baixa qualidade, a disponibilidade desse recurso também é preocupante, tornando-se cada vez mais reduzida a quantidade de mananciais de água em condições de vazáo e qualidade compatíveis com o abastecimento da populaçáo.

Diante dessas preocupaçôes, a água vem sendo discutida quanto ao seu uso, manutenção, quantidade e qualidade para consumo, pois encontra-se sujeita à depreciaçấo de suas características em virtude do crescimento urbano, industrial e rural mal planejado (SiLva; Ueno, 2008). A interferência nos recursos hídricos em áreas rurais é agravada por fatores como os esgotos domésticos e industriais, resíduos sólidos e fertilizantes utilizados na agricultura, podendo comprometer sua qualidade, tornando-as impróprias para consumo humano (Silva; Araújo, 2003). Sendo assim, faz-se necessário o monitoramento constante de sua qualidade, especialmente no meio rural, onde a população, em sua maioria, não é abastecida por empresas de saneamento e a água advém de sistemas alternativos de abastecimento, normalmente sem receber qualquer tipo de tratamento prévio (PNUD, 2006).

No meio rural, o risco de doenças por água contaminada é alto, devido à presença de micro-organismos patogênicos, como Escherichia coli, oriundos principalmente de fossas e pastagens (AMARAL et al., 2003). Os micro-organismos mais utilizados para indicar contaminaçấo fecal de humanos ou animais são os coliformes, cuja presença torna a água imprópria para consumo humano. Água potável, portanto, é aquela livre de E. coli ou coliformes termotolerantes, sendo recomendada sua ausência em $100 \mathrm{~mL}$ (Fortuna et al., 2007).

Nesse sentido, esta comunicação científica tem por objetivo avaliar a qualidade microbiológica e físico-química da água de poços rasos e nascentes de propriedades rurais do município de Dois Vizinhos, Paraná.

Em julho e agosto de 2012, na área rural do município de Dois Vizinhos, Paraná (latitude de 254's, longitude de $53^{\circ} 04^{\prime} \mathrm{W}$ e altitude de $520 \mathrm{~m}$ ), foram selecionadas fontes de água para consumo humano, sendo amostradas 45 nascentes e 45 poços rasos, totalizando 90 amostras. As amostras foram coletadas em frascos estéreis de $100 \mathrm{~mL}$, seguindo os padróes que evitassem a contaminação, sendo a temperatura determinada no ato da coleta com auxílio de termômetro digital. Em seguida, as amostras foram identificadas quanto à origem, acondicionadas em caixas térmicas e levadas ao laboratório, sendo processadas e analisadas no mesmo dia da coleta.

$\mathrm{O} \mathrm{pH}$ foi determinado com peagâmetro digital e a turbidez foi obtida com turbidímetro, sendo os resultados expressos em unidade nefelométricas de turbidez (UNT). Foram realizadas, ainda, análises de coliformes totais e termotolerantes utilizando a técnica de tubos múltiplos e contagem pela técnica de número mais provável (NMP). Foram também realizados testes confirmatórios para coliformes totais e termotolerantes utilizando os meios verde brilhante (VB) e Escherichia coli (EC) (Silva Júnior, 2002).

Analisando a Tabela 1, verificaram-se que, das 45 amostras de água de nascentes, apenas 7 (15,55\%) apresentaram ausência de coliformes termotolerantes, enquanto que para a água de poços rasos, 19 (42,22\%) atenderam aos padrôes de qualidade. Logo, apenas $28,8 \%$ do total de amostras analisadas seguem o padráo ditado pela Portaria n ${ }^{\circ}$ 518/2004 do Ministério da Saúde (Brasil, 2004), a qual define que para águas provindas de nascentes, poços e minas que não receberam nenhum tratamento antes de serem consumidas, é tolerada a presença de coliformes totais, desde que estejam ausentes os termotolerantes. Considerando os resultados obtidos nas contagens de coliformes termotolerantes, comparados com o padrão exigido, pode-se afirmar que as amostras avaliadas apresentaram baixa qualidade higiênico-sanitária.

Esses resultados indicam que a água dos poços e nascentes podem ter sido contaminadas possivelmente com o conteúdo de fossas ou dejetos animas. $\mathrm{O}$ manejo inadequado dos dejetos animais ou de fossas sépticas pode levar à contaminação da água por micro-organismos de origem fecal, Escherichia coli e enterococos, que podem ser carreados do solo para fontes de água superficiais, como córregos e represas, ou sofrerem percolação, podendo atingir lençóis de água subsuperficial ou pouco profundos, causando contaminação da água, principalmente em época de alta pluviosidade (Cogger, 1988).

Em trabalho semelhante ao atual, estudo desenvolvido por Colvara et al. (2009), ao avaliar a qualidade de águas subterrâneas de poços artesianos no sul do Rio Grande do Sul, observou que $100 \%$ das amostras estavam contaminadas por coliformes totais e $70 \%$ delas apresentavam coliformes termotolerantes. Os autores ressaltaram que vários fatores podem ser responsáveis pela contaminação: falta de manutenção do reservatório; localização inadequada do poço; e falta de cuidado e higiene com a água antes do consumo.

Resultado similar é relatado por Amaral et al. (2003) em estudo desenvolvido na regiáo nordeste do estado de São Paulo que, analisando a água para consumo humano em propriedades rurais, verificaram que aproximadamente $96 \%$ das amostras de água de poços rasos analisadas apresentavam-se impróprias para o consumo humano, representando fator de risco à saúde, tendo em vista a altas concentraçóes encontradas.

Em estudo realizado por Nunes et al. (2010), avaliando aspectos microbiológicos e físico-químicos de águas de poços rasos da regiáo de Jaboticabal, São Paulo, verificaram-se que, das 35 propriedades rurais avaliadas abastecidas por poços, $42,8 \%$ apresentavam contaminação fecal decorrente da presença de Escherichia coli, com média igual a 2,1 x 102 NMP.100 m.L1. A Escherichia coli é um micro-organismo considerado como o mais importante indicador de poluiçáo fecal das águas 
Tabela 1. Resultados das análises microbiológicas de água de nascentes e poços rasos.

\begin{tabular}{|c|c|c|c|c|c|c|}
\hline \multirow[t]{2}{*}{ Amostra } & \multicolumn{3}{|c|}{ Nascentes (NMP/100 mL) } & \multicolumn{3}{|c|}{ Poços rasos (NMP/ 100mL) } \\
\hline & $\mathbf{C T}$ & CF & E. coli & CT & CF & E. coli \\
\hline 01 & $1,2 \times 10^{2}$ & $3,3 \times 10^{1}$ & $2,8 \times 10^{1}$ & Ausente & Ausente & Ausente \\
\hline 02 & $2,9 \times 10^{1}$ & $2,5 \times 10^{1}$ & $2,5 \times 10^{1}$ & $3,1 \times 10^{1}$ & $2,0 \times 10^{1}$ & $2,0 \times 10^{1}$ \\
\hline 03 & $1,7 \times 10^{2}$ & $1,7 \times 10^{2}$ & $1,7 \times 10^{2}$ & $4,7 \times 10^{1}$ & $4,5 \times 10^{1}$ & $4,5 \times 10^{1}$ \\
\hline 04 & $4,4 \times 10^{1}$ & $1,7 \times 10^{1}$ & $1,7 \times 10^{1}$ & $2,9 \times 10^{2}$ & $2,8 \times 10^{2}$ & $2,8 \times 10^{2}$ \\
\hline 05 & $1,2 \times 10^{2}$ & $7,0 \times 10^{1}$ & $6,5 \times 10^{1}$ & $2,0 \times 10^{2}$ & $1,8 \times 10^{2}$ & $1,8 \times 10^{2}$ \\
\hline 06 & $1,5 \times 10^{1}$ & $1,5 \times 10^{1}$ & $1,3 \times 10^{1}$ & $2,2 \times 10^{1}$ & $1,8 \times 10^{1}$ & $1,8 \times 10^{1}$ \\
\hline 07 & $4,3 \times 10^{1}$ & $4,3 \times 10^{1}$ & $4,2 \times 10^{1}$ & Ausente & Ausente & Ausente \\
\hline 08 & $4,5 \times 10^{1}$ & $4,5 \times 10^{1}$ & $4,5 \times 10^{1}$ & $5,3 \times 10^{1}$ & $5,3 \times 10^{1}$ & $5,3 \times 10^{1}$ \\
\hline 09 & $1,2 \times 10^{3}$ & $1,2 \times 10^{3}$ & $1,2 \times 10^{3}$ & Ausente & Ausente & Ausente \\
\hline 10 & $1,2 \times 10^{2}$ & $6,8 \times 10^{1}$ & $6,8 \times 10^{1}$ & $7,0 \times 10^{1}$ & $7,0 \times 10^{1}$ & $7,0 \times 10^{1}$ \\
\hline 11 & $1,8 \times 10^{3}$ & $1,2 \times 10^{3}$ & $1,2 \times 10^{3}$ & $2,4 \times 10^{1}$ & $2,1 \times 10^{1}$ & $2,1 \times 10^{1}$ \\
\hline 12 & $1,2 \times 10^{2}$ & $7,0 \times 10^{1}$ & $7,0 \times 10^{1}$ & $1,7 \times 10^{2}$ & $6,1 \times 10^{1}$ & $6,1 \times 10^{1}$ \\
\hline 13 & Ausente & Ausente & Ausente & $7,0 \times 10^{1}$ & $2,6 \times 10^{1}$ & $2,6 \times 10^{1}$ \\
\hline 14 & $2,8 \times 10^{1}$ & $1,3 \times 10^{1}$ & $1,3 \times 10^{1}$ & $7,0 \times 10^{1}$ & $7,0 \times 10^{1}$ & $7,0 \times 10^{1}$ \\
\hline 15 & $1,4 \times 10^{1}$ & $7,8 \times 10^{1}$ & $7,8 \times 10^{1}$ & Ausente & Ausente & Ausente \\
\hline 16 & Ausente & Ausente & Ausente & $7,9 \times 10^{1}$ & $1,0 \times 10^{1}$ & $1,0 \times 10^{1}$ \\
\hline 17 & $4,8 \times 10^{2}$ & $4,3 \times 10^{2}$ & $4,3 \times 10^{2}$ & $3,3 \times 10^{1}$ & $1,3 \times 10^{1}$ & $1,3 \times 10^{1}$ \\
\hline 18 & $1,4 \times 10^{1}$ & $1,2 \times 10^{1}$ & $1,2 \times 10^{1}$ & $13 \times 10^{1}$ & Ausente & Ausente \\
\hline 19 & $3,3 \times 10^{1}$ & $1,3 \times 10^{1}$ & $1,3 \times 10^{1}$ & Ausente & Ausente & Ausente \\
\hline 20 & $1,8 \times 10^{1}$ & $1,8 \times 10^{1}$ & $1,8 \times 10^{1}$ & Ausente & Ausente & Ausente \\
\hline 21 & $2,0 \times 10^{\circ}$ & $2,0 \times 10^{\circ}$ & $2,0 \times 10^{\circ}$ & $6,8 \times 10^{1}$ & $3,2 \times 10^{1}$ & $3,2 \times 10^{1}$ \\
\hline 22 & $4,5 \times 10^{1}$ & $2,6 \times 10^{1}$ & $2,6 \times 10^{1}$ & Ausente & Ausente & Ausente \\
\hline 23 & $8,0 \times 10^{\circ}$ & $4,0 \times 10^{\circ}$ & $4,0 \times 10^{\circ}$ & $2,0 \times 10^{1}$ & $1,5 \times 10^{1}$ & $1,5 \times 10^{1}$ \\
\hline 24 & $2,9 \times 10^{2}$ & $6,3 \times 10^{1}$ & $6,3 \times 10^{1}$ & $1,1 \times 10^{1}$ & Ausente & Ausente \\
\hline 25 & $1,2 \times 10^{3}$ & $7,0 \times 10^{2}$ & $7,0 \times 10^{2}$ & $3,6 \times 10^{1}$ & $3,6 \times 10^{1}$ & $3,6 \times 10^{1}$ \\
\hline 26 & $3,7 \times 10^{1}$ & $3,6 \times 10^{1}$ & $3,6 \times 10^{1}$ & $1,7 \times 10^{1}$ & $1,5 \times 10^{1}$ & $1,5 \times 10^{1}$ \\
\hline 27 & $5,4 \times 10^{2}$ & $2,2 \times 10^{2}$ & $2,2 \times 10^{2}$ & Ausente & Ausente & Ausente \\
\hline 28 & $2,9 \times 10^{2}$ & $2,9 \times 10^{2}$ & $2,9 \times 10^{2}$ & $1,2 \times 10^{1}$ & $4,8 \times 10^{\circ}$ & $4,8 \times 10^{\circ}$ \\
\hline 29 & $5,6 \times 10^{1}$ & $5,6 \times 10^{1}$ & $5,6 \times 10^{1}$ & $2,6 \times 10^{1}$ & $7,3 \times 10^{\circ}$ & $7,3 \times 10^{\circ}$ \\
\hline 30 & $6,0 \times 10^{\circ}$ & $6 \times 10^{\circ}$ & $6,0 \times 10^{\circ}$ & $3,7 \times 10^{1}$ & Ausente & Ausente \\
\hline 31 & $9,4 \times 10^{1}$ & $9,4 \times 10^{1}$ & $9,4 \times 10^{1}$ & Ausente & Ausente & Ausente \\
\hline 32 & $3,2 \times 10^{1}$ & $1,9 \times 10^{1}$ & $1,9 \times 10^{1}$ & $1,2 \times 10^{3}$ & Ausente & Ausente \\
\hline 33 & $1,5 \times 10^{1}$ & $1,5 \times 10^{1}$ & $1,5 \times 10^{1}$ & $2,7 \times 10^{1}$ & Ausente & Ausente \\
\hline 34 & Ausente & Ausente & Ausente & $>2,3 \times 10^{3}$ & $>2,3 \times 10^{3}$ & $>2,3 \times 10^{3}$ \\
\hline 35 & Ausente & Ausente & Ausente & $2,0 \times 10^{1}$ & Ausente & Ausente \\
\hline 36 & $7,0 \times 10^{1}$ & $3,7 \times 10^{1}$ & $3,7 \times 10^{1}$ & $1,7 \times 10^{1}$ & Ausente & Ausente \\
\hline 37 & $1,2 \times 10^{3}$ & $1,2 \times 10^{3}$ & $1,2 \times 10^{3}$ & $3,3 \times 10^{1}$ & Ausente & Ausente \\
\hline 38 & $1,2 \times 10^{3}$ & $7,0 \times 10^{2}$ & $7,0 \times 10^{2}$ & $6,0 \times 10^{1}$ & $4,2 \times 10^{1}$ & $4,2 \times 10^{1}$ \\
\hline 39 & $2,9 \times 10^{2}$ & $6,3 \times 10^{1}$ & $6,3 \times 10^{1}$ & $1,9 \times 10^{1}$ & $1,7 \times 10^{1}$ & $1,7 \times 10^{1}$ \\
\hline 40 & $2,9 \times 10^{2}$ & $2,9 \times 10^{2}$ & $2,9 \times 10^{2}$ & $3,7 \times 10^{1}$ & $3,7 \times 10^{1}$ & $3,7 \times 10^{1}$ \\
\hline 41 & $5,4 \times 10^{2}$ & $2,2 \times 10^{2}$ & $2,2 \times 10^{2}$ & Ausente & Ausente & Ausente \\
\hline 42 & $3,7 \times 10^{1}$ & $3,6 \times 10^{1}$ & $3,6 \times 10^{1}$ & Ausente & Ausente & Ausente \\
\hline 43 & Ausente & Ausente & Ausente & $3,7 \times 10^{1}$ & $1,4 \times 10^{1}$ & $1,4 \times 10^{1}$ \\
\hline 44 & Ausente & Ausente & Ausente & $7,0 \times 10^{1}$ & $4,4 \times 10^{1}$ & $4,4 \times 10^{1}$ \\
\hline 45 & Ausente & Ausente & Ausente & $3,5 \times 10^{1}$ & $3,1 \times 10^{1}$ & $3,1 \times 10^{1}$ \\
\hline
\end{tabular}

CT: coliformes totais; CF: coliformes fecais. 
(Dawson; SARTory, 2000) e, portanto, de risco à saúde quando se consome água em que ele está presente. Desse modo, a utilização de fontes alternativas de água pela populaçâoo rural a expõe a doenças de veiculaçấo hídrica, pois não há conhecimento dessas populaçôes sobre a falta de qualidade sanitária da água consumida sem nenhum tipo de tratamento associado à falsa ideia de que a água subterrânea seja potável, além da falta de condiçóes sanitárias satisfatórias na zona rural (QueIroz et al., 2002).

Em relação à turbidez (Tabela 2), das 90 amostras analisadas, apenas $46(51,10 \%)$ atendem à exigência ideal de 1,0 UTN. Outras 42 amostras (46,70\%) estão dentro do limite de tolerância de 5,0 UTN, enquanto que 2 (2,20\%) estấo acima desse valor, considerado o máximo aceitável. Resultado semelhante foi descrito por Nunes et al. (2010), os quais verificaram que dentre as 35 propriedades rurais, $45,7 \%$ estavam fora do padráo de potabilidade quanto a esse parâmetro. É importante destacar que, para garantir a qualidade microbiológica da água, o padrão de turbidez deve ser monitorado, pois a presença de patógenos como, por exemplo, Cryptosporidium spp., tem sido associada à turbidez, de forma que, quanto maior a turbidez da água, maior a possibilidade de se encontrar o parasita (Medema et al., 1998).

Segundo a Portaria no $518 / 2004$, não existem valores limites para o padrão temperatura. No entanto, essas análises foram realizadas observando-se valores entre 21 e $26,7^{\circ} \mathrm{C}$. Essa análise e o conhecimento da variação desses resultados são de grande importância, pois a temperatura influencia os processos biológicos, reaçóes químicas e bioquímicas, bem como a solubilidade dos gases dissolvidos e sais minerais na água (MACEDO, 2004).

$\mathrm{O}$ valor do $\mathrm{pH}$ é importante, pois apresenta forte relação com o crescimento bacteriano, uma vez que para a maioria das bactérias o $\mathrm{pH}$ ótimo para seu desenvolvimento oscila entre 6,5 e 7,5 (Soares; Maia, 1999). Segundo a Portaria $\mathrm{n}^{\circ} 518 / 2004$, recomenda-se que o $\mathrm{pH}$ da água para consumo humano mantenha-se na faixa de 6,0 a 9,5 , sendo que nas amostras avaliadas o $\mathrm{pH}$ variou entre 6,1 e 8,3, atendendo, portanto, à legislação vigente. Resultados semelhantes foram descritos por MaChado et al. (2012), que avaliaram os parâmetros físico-químicos da água de nascentes na cidade de Avaré no estado de Sáo Paulo, destacando que, das 60 amostras avaliadas, todas atenderam à legislação quanto a esse parâmetro.

Diante do exposto, fica evidente que o consumo de água de poços rasos e nascentes na situaçáo avaliada pode representar risco à saúde publica, uma vez que elevado percentual das amostras encontra-se em desacordo com a legislação vigente, não apresentando condiçóes de potabilidade, sendo, portanto, capaz de transmitir enfermidades de veiculação hídrica.
Tabela 2. Análises físico-químicas de áqua de nascentes e poços rasos.

\begin{tabular}{|c|c|c|c|c|c|c|}
\hline \multirow{2}{*}{ Amostra } & \multicolumn{3}{|c|}{ Nascentes } & \multicolumn{3}{|c|}{ Poços rasos } \\
\hline & $\mathrm{pH}$ & $\mathrm{T}\left({ }^{\circ} \mathrm{C}\right)$ & Turbidez & $\mathrm{pH}$ & $\mathrm{T}\left({ }^{\circ} \mathrm{C}\right)$ & Turbidez \\
\hline 1 & 6,8 & 22,0 & 2,33 & 7,4 & 22,0 & 0,53 \\
\hline 2 & 6,3 & 22,3 & 1,29 & 7,4 & 21,6 & 3,75 \\
\hline 3 & 6,4 & 24,0 & 2,77 & 7,1 & 23,0 & 2,55 \\
\hline 4 & 6,5 & 25,0 & 0,97 & 6,4 & 23,1 & 4,95 \\
\hline 5 & 6,4 & 23,8 & 2,49 & 6,8 & 22,8 & 0,45 \\
\hline 6 & 6,9 & 25,0 & 0,38 & 6,9 & 22,4 & 1,64 \\
\hline 7 & 6,4 & 26,0 & 0,31 & 7,2 & 21,0 & 0,26 \\
\hline 8 & 6,8 & 23,0 & 0,24 & 6,4 & 24,0 & 0,30 \\
\hline 9 & 6,7 & 23,5 & 7,25 & 7,0 & 22,9 & 1,15 \\
\hline 10 & 6,8 & 25,1 & 0,33 & 7,2 & 24,1 & 0,64 \\
\hline 11 & 6,9 & 24,6 & 0,20 & 6,5 & 22,9 & 0,46 \\
\hline 12 & 7,1 & 24,0 & 0,42 & 7,0 & 23,4 & 0,32 \\
\hline 13 & 7,2 & 24,0 & 2,23 & 6,9 & 22,1 & 0,43 \\
\hline 14 & 6,9 & 22,0 & 1,47 & 6,9 & 22,0 & 0,61 \\
\hline 15 & 6,8 & 23,0 & 1,32 & 7,1 & 23,0 & 0,42 \\
\hline 16 & 6,5 & 22,0 & 1,51 & 6,6 & 23,0 & 0,36 \\
\hline 17 & 6,3 & 24,5 & 1,28 & 6,4 & 23,1 & 0,40 \\
\hline 18 & 6,4 & 23,0 & 0,54 & 7,2 & 24,0 & 1,03 \\
\hline 19 & 6,5 & 23,2 & 2,42 & 7,2 & 24,3 & 1,08 \\
\hline 20 & 6,5 & 22,0 & 0,73 & 7,1 & 23,0 & 1,81 \\
\hline 21 & 6,3 & 22,3 & 0,30 & 6,8 & 23,6 & 2,95 \\
\hline 22 & 6,6 & 24,3 & 0,36 & 6,9 & 24,0 & 1,44 \\
\hline 23 & 6,4 & 25,0 & 0,32 & 7,2 & 23,5 & 1,72 \\
\hline 24 & 6,8 & 25,0 & 0,29 & 7,0 & 22,0 & 1,55 \\
\hline 25 & 6,9 & 26,0 & 0,25 & 6,8 & 23,7 & 2,97 \\
\hline 26 & 6,4 & 25,1 & 0,31 & 7,0 & 23,6 & 0,25 \\
\hline 27 & 6,1 & 21,0 & 1,31 & 7,1 & 24,0 & 0,39 \\
\hline 28 & 6,4 & 21,9 & 0,75 & 6,5 & 22,0 & 0,47 \\
\hline 29 & 6,3 & 22,9 & 1,33 & 7,2 & 21,9 & 0,56 \\
\hline 30 & 6,7 & 24,6 & 3,23 & 7,3 & 22,1 & 0,42 \\
\hline 31 & 6,9 & 25,3 & 1,56 & 7,5 & 25,0 & 0,71 \\
\hline 32 & 7,2 & 23,7 & 4,83 & 6,8 & 24,6 & 0,41 \\
\hline 33 & 7,0 & 24,2 & 3,06 & 6,9 & 24,5 & 0,26 \\
\hline 34 & 8,3 & 24,7 & 3,20 & 7,4 & 25,2 & 6,92 \\
\hline 35 & 8,2 & 24,3 & 1,06 & 6,7 & 24,0 & 0,28 \\
\hline 36 & 7,9 & 26,2 & 0,85 & 6,7 & 22,4 & 0,30 \\
\hline 37 & 8,1 & 26,7 & 0,99 & 6,6 & 24,6 & 0,46 \\
\hline 38 & 6,9 & 24,8 & 1,09 & 7,4 & 23,0 & 2,00 \\
\hline 39 & 6,7 & 23,8 & 0,60 & 7,2 & 22,5 & 2,05 \\
\hline 40 & 7,6 & 24,8 & 0,64 & 7,7 & 24,3 & 0,67 \\
\hline 41 & 7,5 & 24,7 & 0,81 & 7,2 & 23,6 & 1,03 \\
\hline 42 & 7,0 & 22,1 & 2,31 & 7,0 & 23,6 & 1,18 \\
\hline 43 & 6,9 & 24,0 & 1,06 & 6,4 & 22,2 & 1,24 \\
\hline 44 & 6,8 & 24,5 & 1,63 & 6,9 & 23,4 & 1,36 \\
\hline 45 & 7,2 & 25,0 & 0,53 & 6,5 & 24,2 & 3,39 \\
\hline
\end{tabular}




\section{REFERÊNCIAS}

AMARAL, L.A.; NADER FILHO, A.; ROSSI JUNIOR, O.D.; FERREIRA, F.L.A.; BARROS L.S.S. Água de consumo humano como fator de risco à saúde em propriedades rurais. Revista de Saúde Pública, v.37, n.4, p.510-514, 2003.

BRASIL. MINISTÉRIO DA SAÚDE. Portaria no 518 , de 25 de março de 2004. Estabelece os procedimentos e responsabilidades relativos ao controle e vigilância da qualidade da água para consumo humano e seu padrão de potabilidade, e dá outras providências. Diário Oficial da União, Brasília, 2004.

COGGER, C. On-site septic systems: the risk of groundwater contamination. Journal of Environmental Health, v.51, n.1, p.12-16, 1988.

COLVARA, J.G.; LIMA, A.S.; SILVA, W.P. Avaliação da contaminação de água subterrânea em poços artesianos no sul do Rio Grande do Sul. Brazilian Journal of Food Technology, Campinas, v.2, p. $11-14,2009$.

DAWSON, D.J.; SARTORY, D.P. Microbiological safety of water. British Medical Bulletin, v.56, p.74-83, 2000.

FORTUNA, J.L.; RODRIGUES, M.T.; SOUZA, S.L.; SOUZA, L. Análise microbiológica da água de bebedouros do campus da Universidade Federal de Juiz de Fora: coliformes totais e termotolerantes. Revista Higiene Alimentar, v.21, n.154, p. 103-105, 2007.

GERMANO, P.M.L.; GERMANO, M.I.S. A áqua: um problema de segurança nacional. Revista Higiene Alimentar, v.15, p.15$18,2001$.

MACEDO, J.A.B. Águas \& águas. Belo Horizonte: CRQ-MG, 2004. 977p.
MACHADO, R.P.; AUGUSTO, R.S.; MARTINS, O. A. Análise química da água de nascentes nas cidades de Avaré e Cerqueira César, São Paulo. Revista Eletrônica de Educação e Ciência, v.2, n.3, p.40-44, 2012.

MEDEMA, G.J.; SCHETS, F.M.; TEUNIS, P.F.M. Sedimentation of free and attached Cryptosporidium oocysts and Giardia cysts in water. Applied and Environmental Microbiology, v.64, p.4460-4466, 1998.

NUNES, A.P.; LOPES, L.G.; REZENDE, P.F.; AMARAL, L.A. Qualidade da áqua subterrânea e percepção dos consumidores em propriedades rurais. Nucleus, v.7, n.2, p.95-104, 2010.

PNUD. PROGRAMA DAS NAÇÕES UNIDAS PARA O DESENVOLVIMENTO. Relatório do Desenvolvimento Humano 2006. A água para lá da escassez: poder, pobreza e a crise mundial da água. New York: PNUD, 2006. 1101 p.

QUEIROZ, M.F.; CARDOSO, M.C.S.; SANTANA, E.M.; GOMES, A.B.; RIQUE, S.M.N.; LOPES, C.M. A qualidade da água de consumo humano e as doenças diarreicas agudas no município de Cabo de Santo Agostinho, PE. Brazilian Journal of Epidemiology, suplemento especial, p.456- 462, 2002.

SILVA, A.B.A.; UENO, M. Qualidade sanitária das áquas do rio Uma, São Paulo, no período das chuvas. Revista Biociências, v. 14, n. 1, p.82-86, 2008

SILVA JÚNIOR, E.A. Manual de controle higiênico sanitário em alimentos. 5a ed. São Paulo: Varela, 2002. 385p.

SILVA, R.C.A.; ARAÚJO, T.M. Qualidade da água do manancial subterrâneo em áreas urbanas de Feira de Santana (BA). Ciência ๑ Saúde Coletiva, v.8, n.4, p.1019-1028, 2003.

SOARES, J.B.; MAIA, A.C.F. Água: microbiologia e tratamento. Fortaleza: UFC, 1999. 215p. 